\title{
Separation of Benzene and Cyclohexane by Nonporous Adaptive Crystals of a Hybrid[3]arene
}

\author{
Jiong Zhou, Guocan Yu,* Qing Li, Mengbin Wang, and Feihe Huang*
}

State Key Laboratory of Chemical Engineering, Center for Chemistry of High-Performance \& Novel Materials, Department of Chemistry, Zhejiang University, Hangzhou 310027, P. R. China; Fax and Tel: +86-571-8795-3189;

Email: guocanyu@zju.edu.cn; fhuang@zju.edu.cn

\section{Supporting Information (18 pages)}

1. Materials $\quad$ S2

2. Methods S2

3. Synthesis of Hybrid[3]arene $1 \quad$ S4

4. Crystallographic Data S5

5. Characterization of Activated 1 Crystals $(1 \alpha) \quad$ S6

6. Single-Component $\boldsymbol{B} z / C y$ Adsorption Experiments $\quad \mathrm{S} 8$

7. Noncovalent Interactions Analysis in Single Crystal Structure of Bz@1

8. Uptake from a $\boldsymbol{B z} / \boldsymbol{C y}$ Mixture by $\mathbf{1} \alpha \quad \mathrm{S} 15$

$\begin{array}{ll}\text { 9. Recyclability of } \mathbf{1} \alpha & \text { S17 }\end{array}$

$\begin{array}{ll}\text { 10. References } & \text { S18 }\end{array}$ 


\section{Materials}

All chemicals, including benzene $(\mathbf{B z})$ and cyclohexane $(\mathbf{C y})$, were purchased and used as received. Hybrid[3] arene (1) was synthesized as described previously. ${ }^{\mathrm{S} 1}$ Activated crystalline $\mathbf{1}(\mathbf{1} \alpha)$ was recrystallized from acetone and dried under vacuum at $150{ }^{\circ} \mathrm{C}$ overnight.

\section{Methods}

\subsection{Solution NMR}

Solution ${ }^{1} \mathrm{H}$ NMR spectra were recorded at $400.13 \mathrm{MHz}$ using a Bruker Avance 400 NMR spectrometer.

\subsection{Powder X-Ray Diffraction}

Powder X-ray diffraction (PXRD) data were collected on a Rigaku Ultimate-IV X-ray diffractometer operating at $40 \mathrm{kV} / 30 \mathrm{~mA}$ using the $\mathrm{Cu} \mathrm{K} \alpha$ line $(\lambda=1.5418 \AA$ ). Data were measured over the range of $5-45^{\circ}$ in $5^{\circ} / \mathrm{min}$ steps over $8 \mathrm{~min}$.

\subsection{Thermogravimetric Analysis}

Thermogravimetric analysis (TGA) was carried out using a Q5000IR analyzer (TA Instruments) with an automated vertical overhead thermobalance. The samples were heated at $10{ }^{\circ} \mathrm{C} / \mathrm{min}$ using $\mathrm{N}_{2}$ as the protective gas.

\subsection{Single Crystal Growth}

Single crystals of Bz@1 were grown by slow evaporation: $5 \mathrm{mg}$ of dry $\mathbf{1}$ were put in a small vial where $1 \mathrm{~mL}$ of $\mathbf{B z}$ was added. The resultant transparent solution was allowed to evaporate slowly to give colorless crystals in 2 to 3 days.

\subsection{Single Crystal X-ray Diffraction}

Single crystal X-ray diffraction data were collected on a Bruker D8 VENTURE CMOS X-ray diffractometer with graphite monochromated Mo K $\alpha$ radiation $(\lambda=0.71073 \AA)$.

\subsection{Gas Sorption Measurement}

Low-pressure gas adsorption measurements were performed on a Micrometritics Accelerated Surface Area and Porosimetry System (ASAP) 2020 surface area analyzer. Samples were degassed under dynamic vacuum for $12 \mathrm{~h}$ at $60{ }^{\circ} \mathrm{C}$ prior to each measurement. $\mathrm{N}_{2}$ isotherms were measured using a liquid nitrogen bath $(77 \mathrm{~K})$. 


\subsection{Vapor Sorption Measurement}

$\mathbf{B z}$ and $\mathbf{C y}$ sorption isotherms were measured via a Micromeritic 3Flex instrument. Samples were degassed under dynamic vacuum for 12 hours at $80{ }^{\circ} \mathrm{C}$ prior to each measurement. The isotherms were collected at $25^{\circ} \mathrm{C}$ by monitoring the volume changes.

\subsection{Gas Chromatography}

Head Space Gas Chromatographic (HS-GC) Analysis: HS-GC measurements were carried out using an Agilent 7890B instrument configured with an FID detector and a DB-624 column $(30 \mathrm{~m} \times 0.53 \mathrm{~mm} \times$ $3.0 \mu \mathrm{m})$. Samples were analyzed using headspace injections and were performed by incubating the sample at $100{ }^{\circ} \mathrm{C}$ for $10 \mathrm{~min}$ followed by sampling $1 \mathrm{~mL}$ of the headspace. The following GC method was used: the oven was programmed from $50{ }^{\circ} \mathrm{C}$ ramped in $10{ }^{\circ} \mathrm{C} \mathrm{min}{ }^{-1}$ increments to $150{ }^{\circ} \mathrm{C}$ with 15 min hold; the total run time was $25 \mathrm{~min}$; the injection temperature was $250{ }^{\circ} \mathrm{C}$; the detector temperature was $280{ }^{\circ} \mathrm{C}$ with nitrogen, air, and make-up flow rates of 35,350 , and $35 \mathrm{~mL} \mathrm{~min}^{-1}$, respectively; the helium (carrier gas) flow rate was $3.0 \mathrm{~mL} \mathrm{~min}^{-1}$. The samples were injected in the split mode (30:1). 


\section{Synthesis of Hybrid[3]arene 1}

Scheme S1. Synthetic Route to Hybrid[3]arene 1

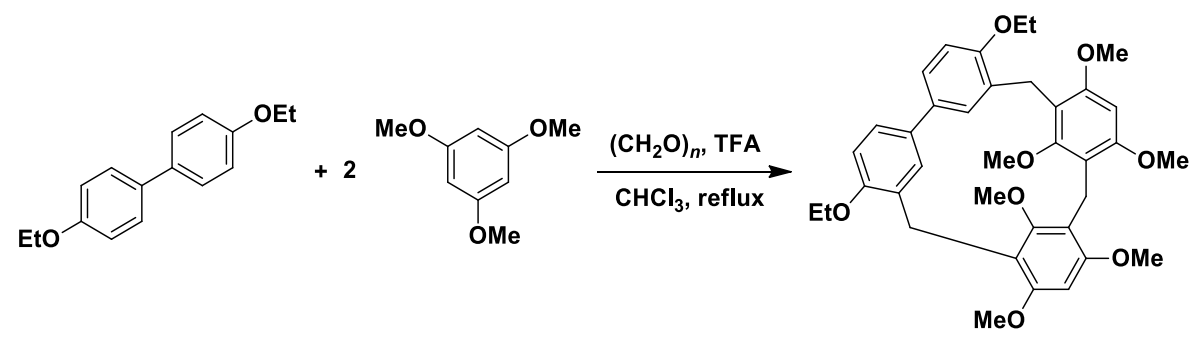

1

Hybrid[3]arene 1 was prepared according to a literature procedure. ${ }^{\mathrm{S} 1}$ 


\section{Crystallographic Data}

Table S1. Experimental single crystal X-ray data for $\mathbf{B z} @ \mathbf{1}$.

\begin{tabular}{|c|c|}
\hline Formula & Bz@1 \\
\hline Crystallization Solvent & benzene \\
\hline Collection Temperature $(\mathrm{K})$ & 273 \\
\hline Formula & $\mathrm{C}_{43} \mathrm{H}_{48} \mathrm{O}_{8}$ \\
\hline Formula Weight & 692.81 \\
\hline Crystal System & Triclinic \\
\hline Space Group & $\mathrm{P}-1$ \\
\hline$a[\AA]$ & $10.7525(3)$ \\
\hline$b[\AA]$ & $13.2311(4)$ \\
\hline$c[\AA]$ & $15.5424(4)$ \\
\hline$\alpha\left[^{0}\right]$ & $105.2250(10)$ \\
\hline$\beta\left[^{\circ}\right]$ & $105.9030(10)$ \\
\hline$\gamma\left[^{\circ}\right]$ & $108.3520(10)$ \\
\hline$V\left[\AA^{3}\right]$ & $1865.15(9)$ \\
\hline$Z$ & 2 \\
\hline$D_{\text {calcd }}\left[\mathrm{g} \mathrm{cm}^{-3}\right]$ & 1.234 \\
\hline Absorption coefficient $\left(\mathrm{mm}^{-1}\right)$ & 0.084 \\
\hline$F(000)$ & 740 \\
\hline Theta range $\left[{ }^{\circ}\right]$ & $2.90-26.13$ \\
\hline Reflections collected / unique & $11849 / 7373[R($ int $)=0.0158]$ \\
\hline Data / restraints / parameters & $7373 / 0 / 468$ \\
\hline Final $R$ indices $[I>2 \sigma(I)]$ & $R_{1}=0.1118, w R_{2}=0.1118$ \\
\hline$R$ indices (all data) & $R_{1}=0.1186, w R_{2}=0.1186$ \\
\hline Goodness-of-fit on $F^{2}$ & 1.013 \\
\hline Largest difference peak and & 0.414 and -0.341 \\
\hline \multicolumn{2}{|l|}{ hole $\left[\right.$ e. $\left.\mathrm{A}^{-3}\right]$} \\
\hline CCDC & 1962323 \\
\hline
\end{tabular}


5. Characterization of Activated 1 Crystals (1 $\alpha)$

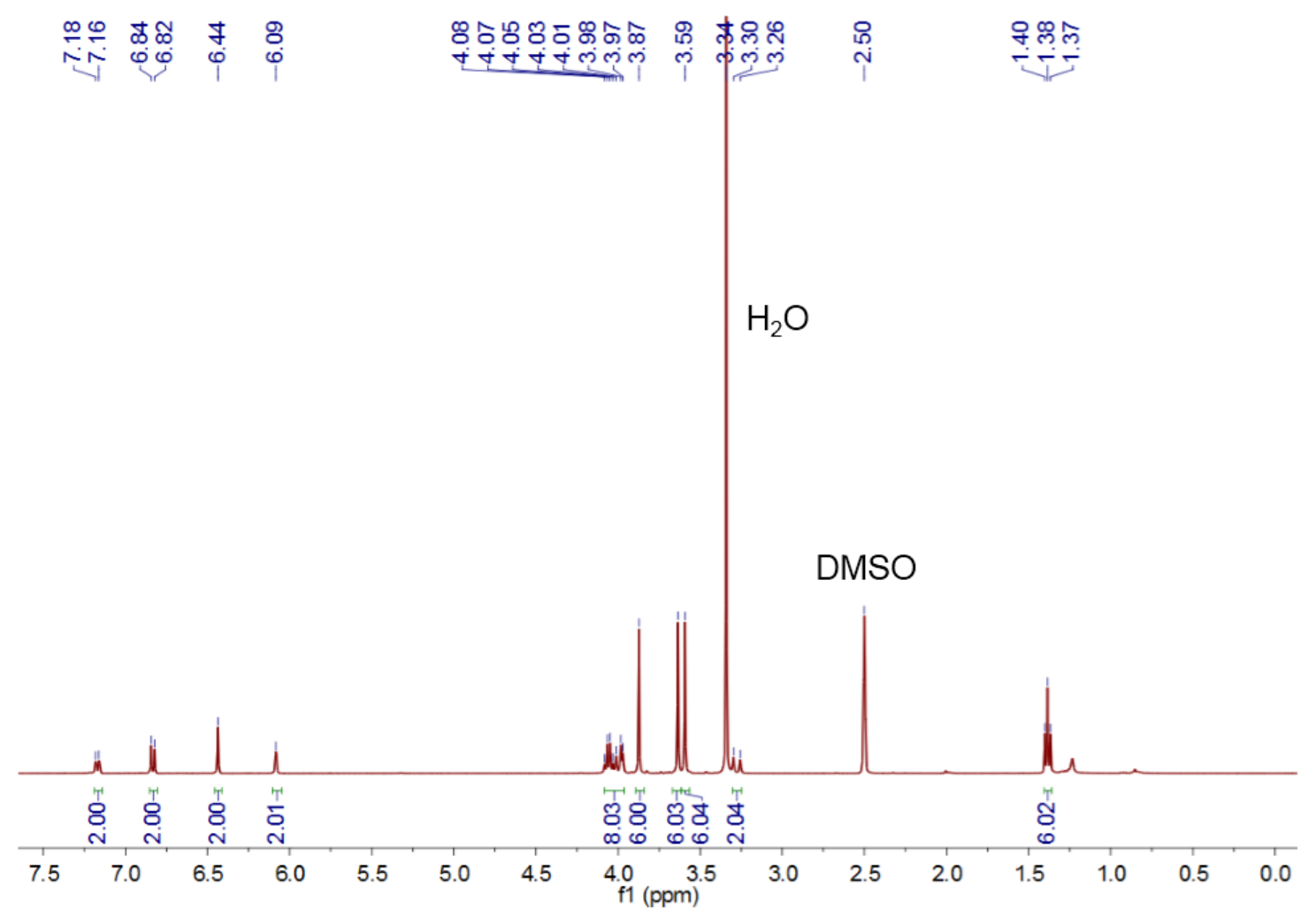

Figure S1. ${ }^{1} \mathrm{H}$ NMR spectrum (400 MHz, DMSO- $d_{6}, 293 \mathrm{~K}$ ) of $1 \alpha$.

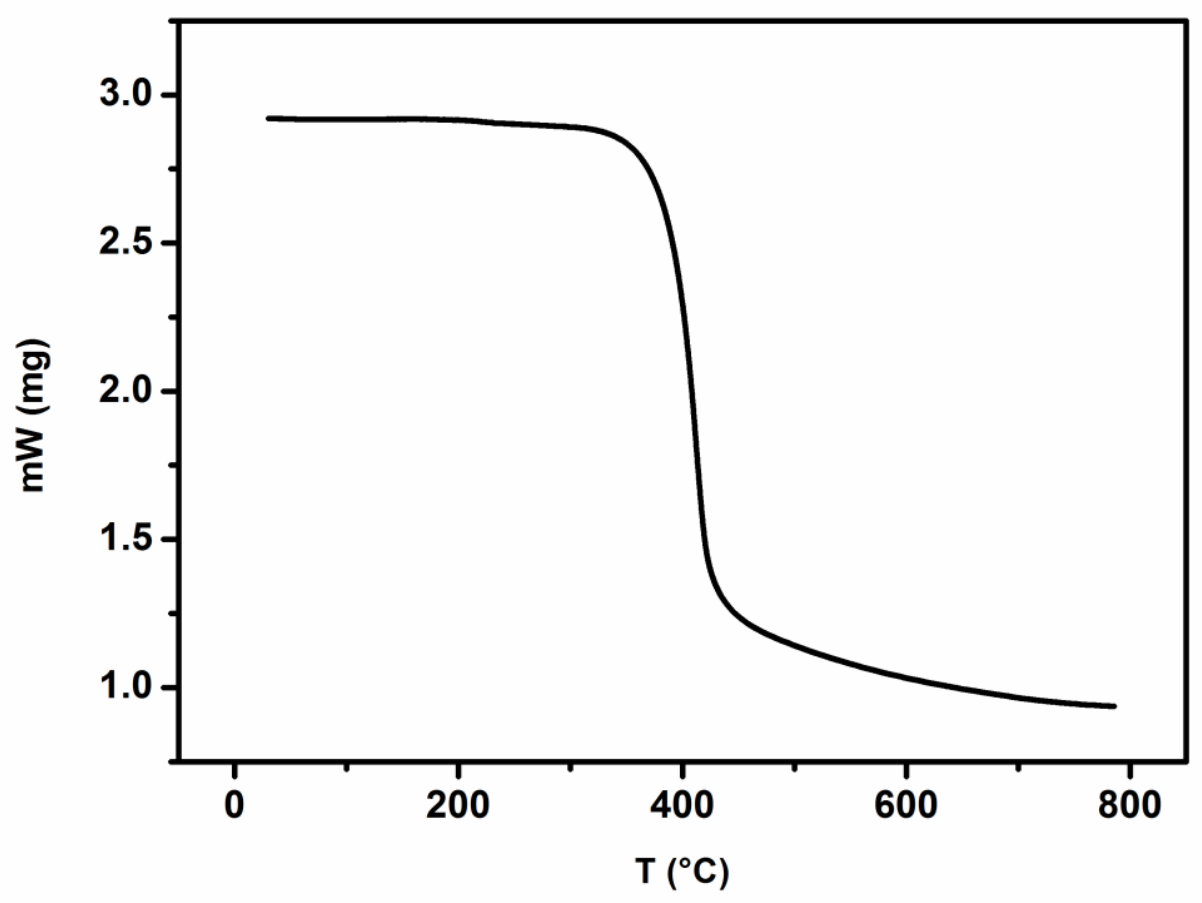

Figure S2. Thermogravimetric analysis of $\mathbf{1} \alpha$. 


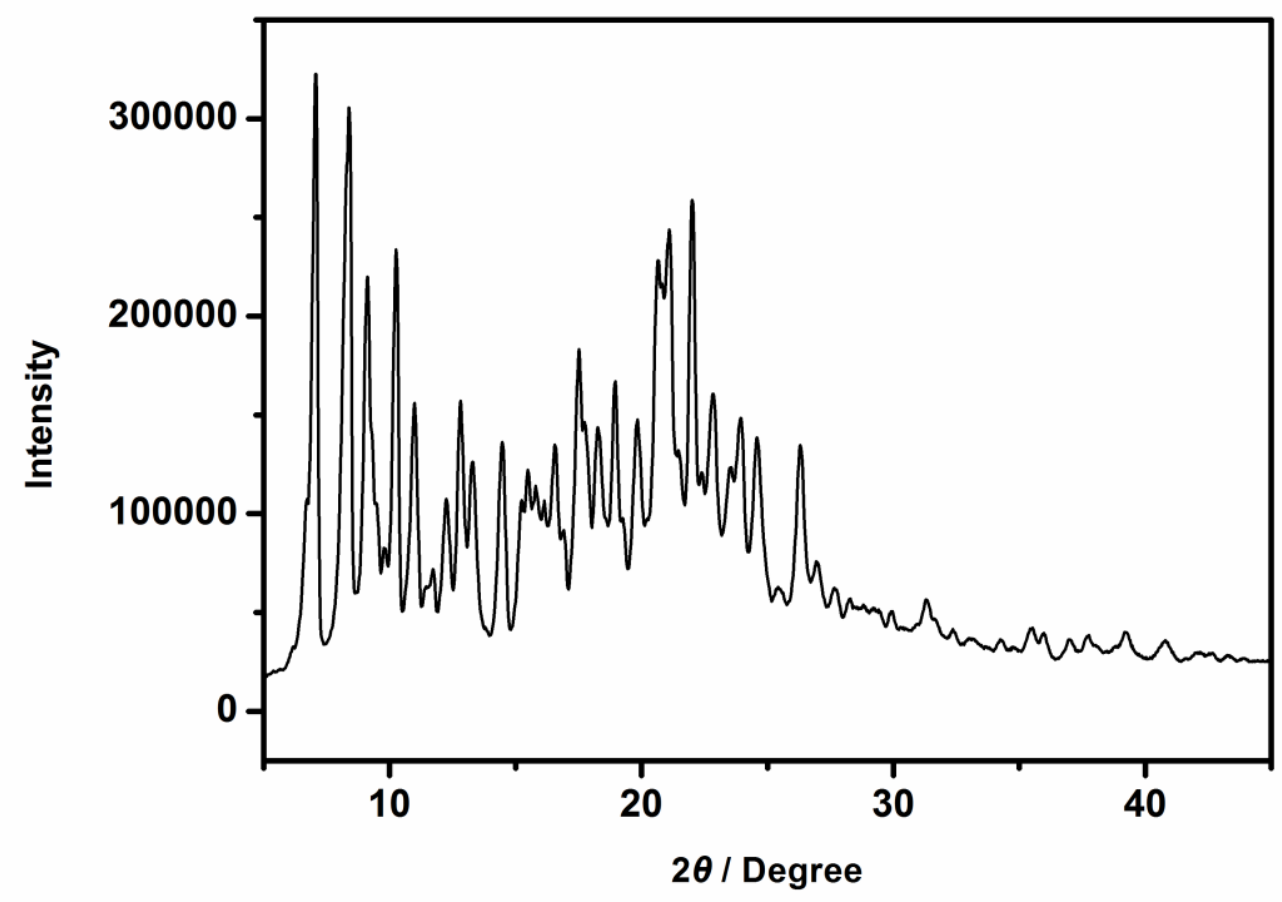

Figure S3. Powder X-ray diffraction pattern of $1 \alpha$.

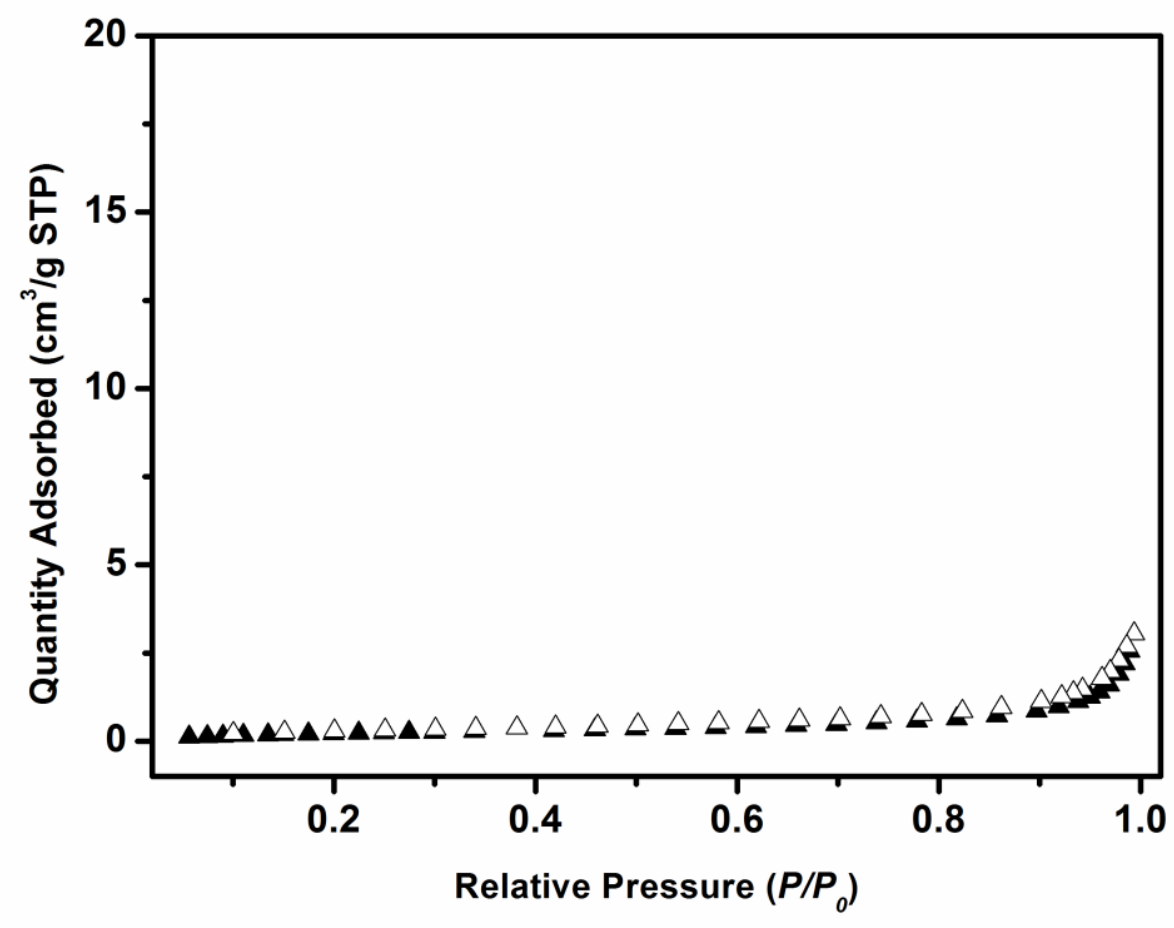

Figure S4. $\mathrm{N}_{2}$ adsorption isotherm of $1 \alpha$. The BET surface area value is $0.8995 \mathrm{~m}^{2} / \mathrm{g}$. Adsorption, closed symbols; desorption, open symbols. 


\section{Single-Component Bz/Cy Adsorption Experiments}

${ }^{1} \mathrm{H}$ NMR experiments were performed by dissolving $1 \alpha$ after vapor sorption in DMSO- $d_{6}$. TGA profiles were recorded using $1 \alpha$ after vapor sorption.

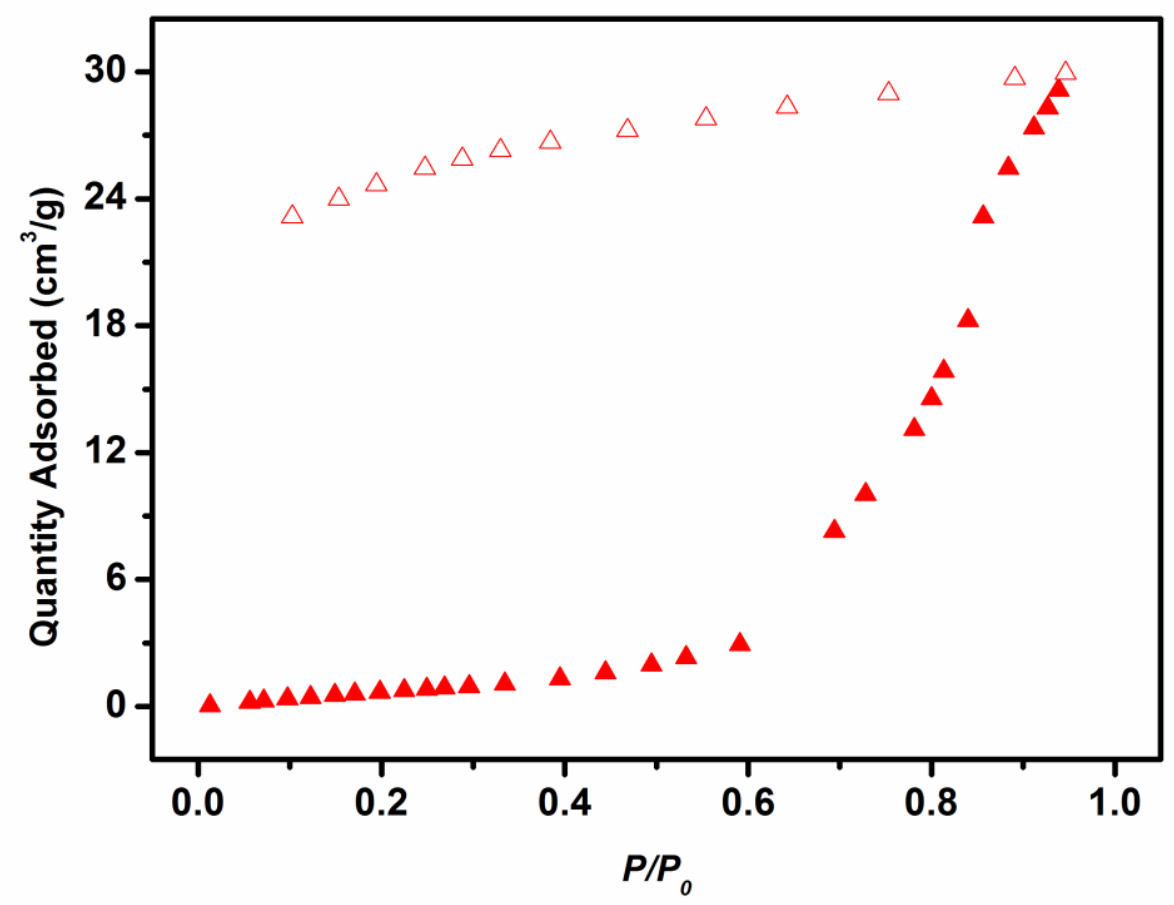

Figure S5. Vapor sorption isotherms of $\mathbf{1} \alpha$ towards Bz. Adsorption, solid symbols; desorption, open symbols. 


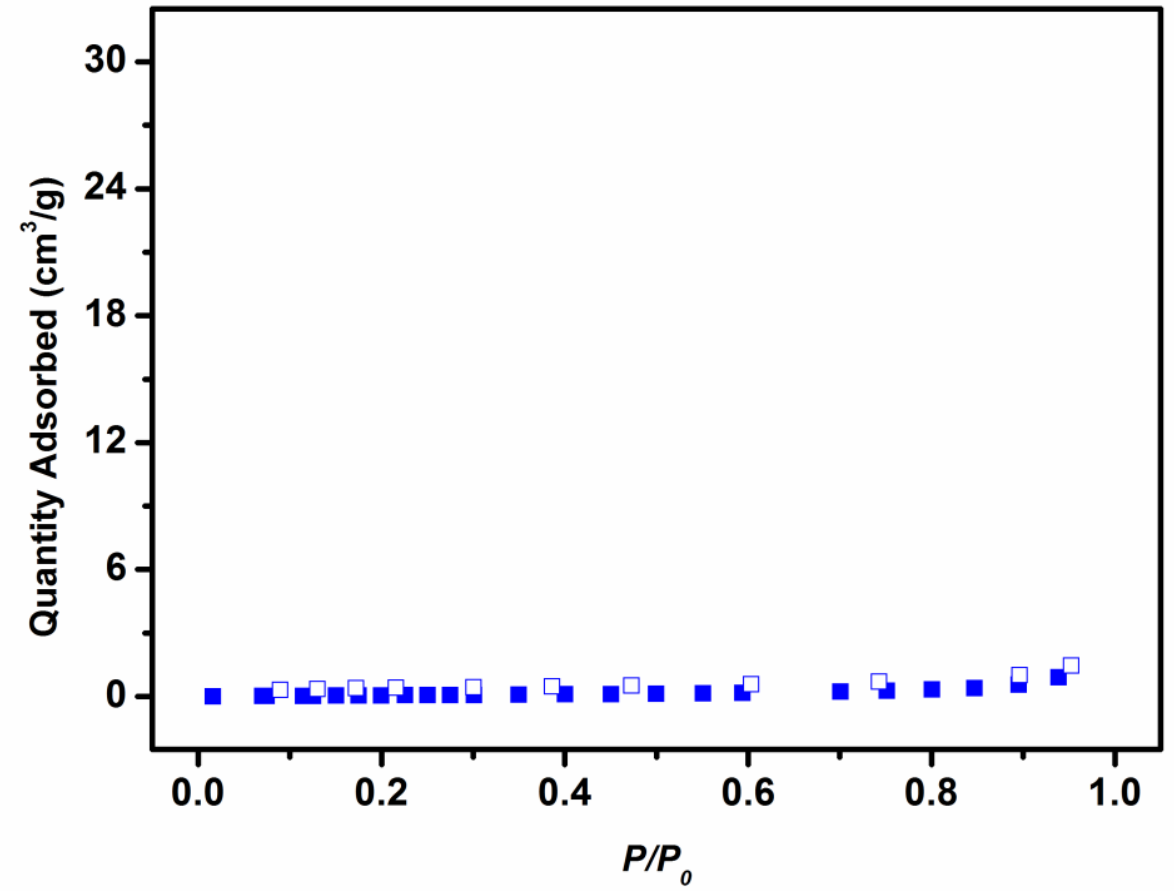

Figure S6. Vapor sorption isotherms of $\mathbf{1} \alpha$ towards Cy. Adsorption, solid symbols; desorption, open symbols. 


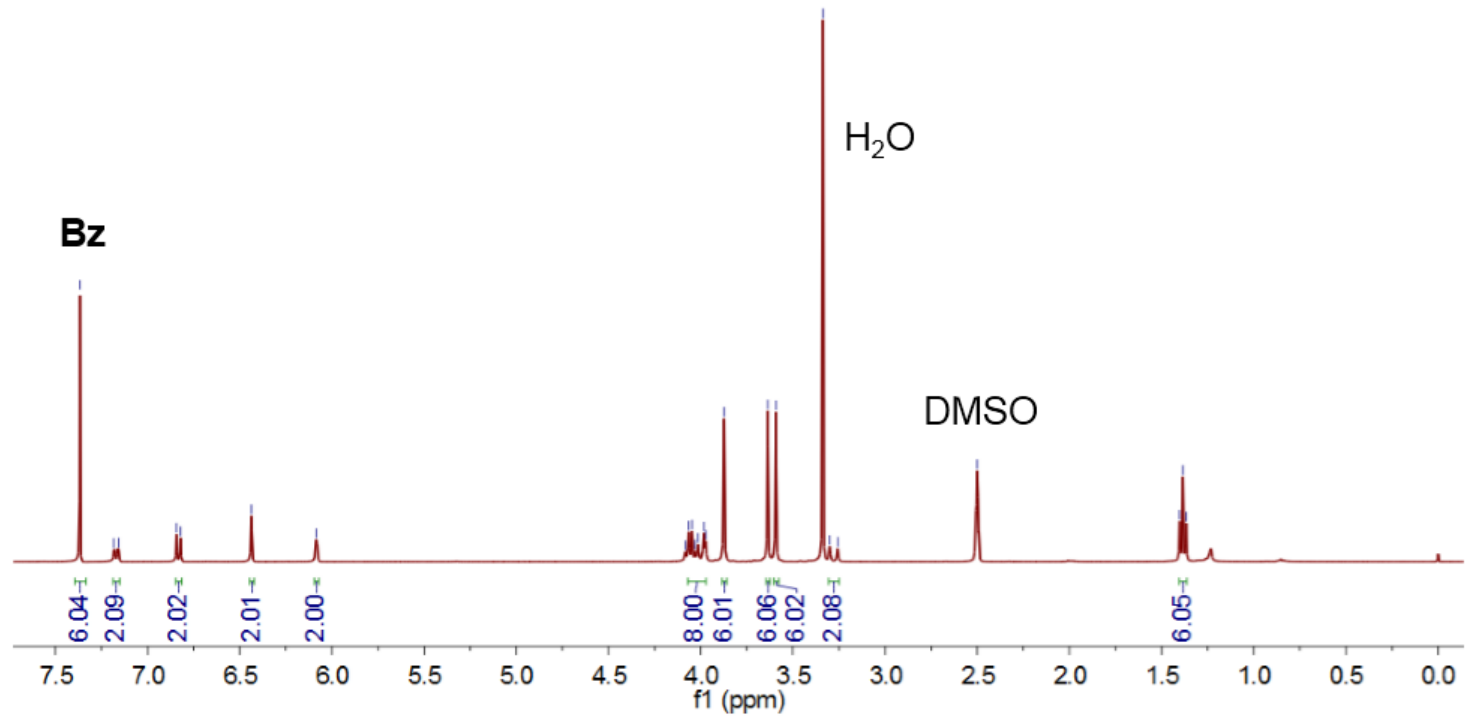

Figure S7. ${ }^{1} \mathrm{H}$ NMR spectrum (400 MHz, DMSO-d $d_{6}, 293 \mathrm{~K}$ ) of $1 \alpha$ after sorption of $\mathbf{B z}$ vapor for $12 \mathrm{~h}$.

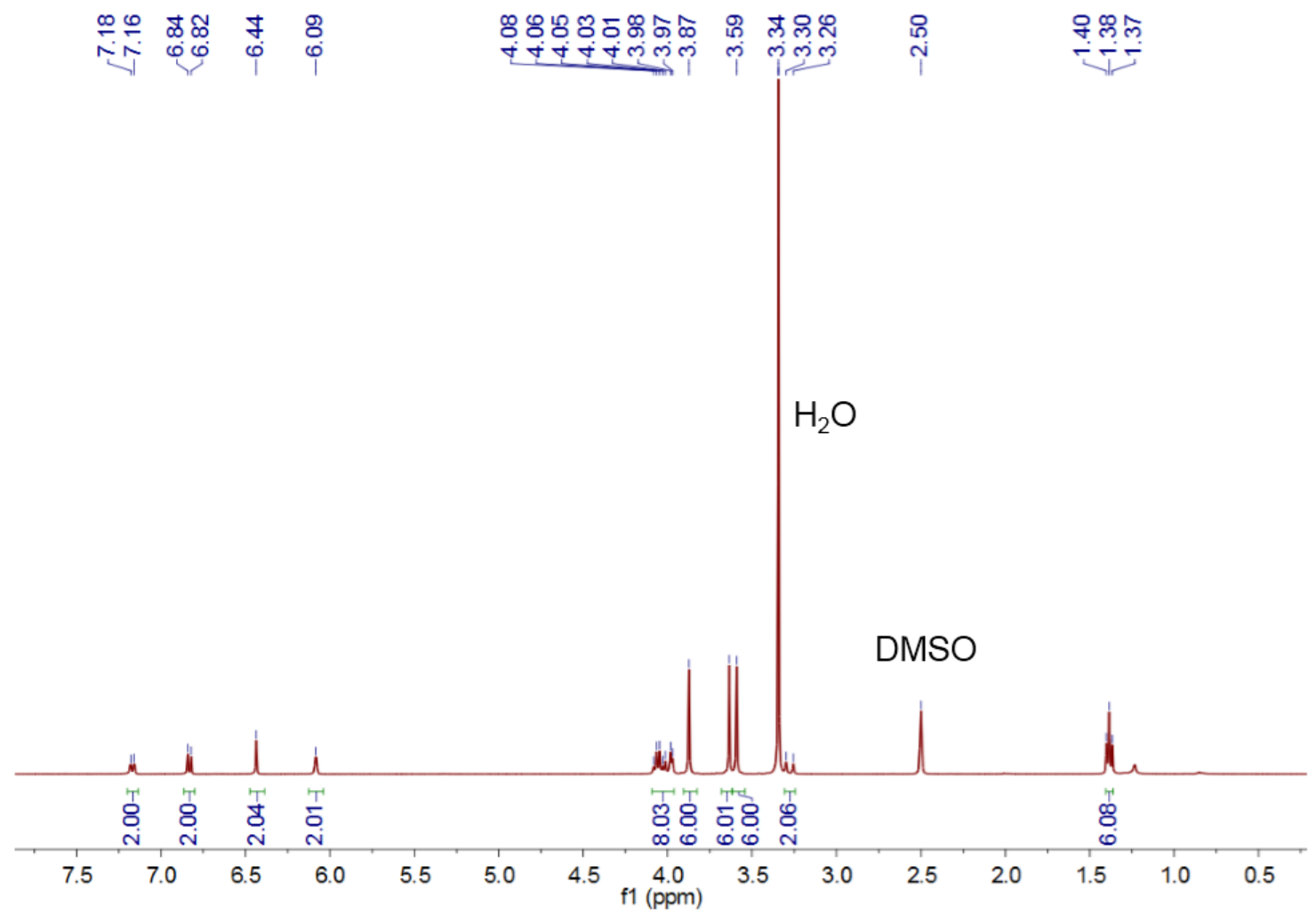

Figure S8. ${ }^{1} \mathrm{H}$ NMR spectrum (400 MHz, DMSO- $d_{6}, 293 \mathrm{~K}$ ) of $\mathbf{1} \alpha$ after sorption of $\mathbf{C y}$ vapor for $12 \mathrm{~h}$. 


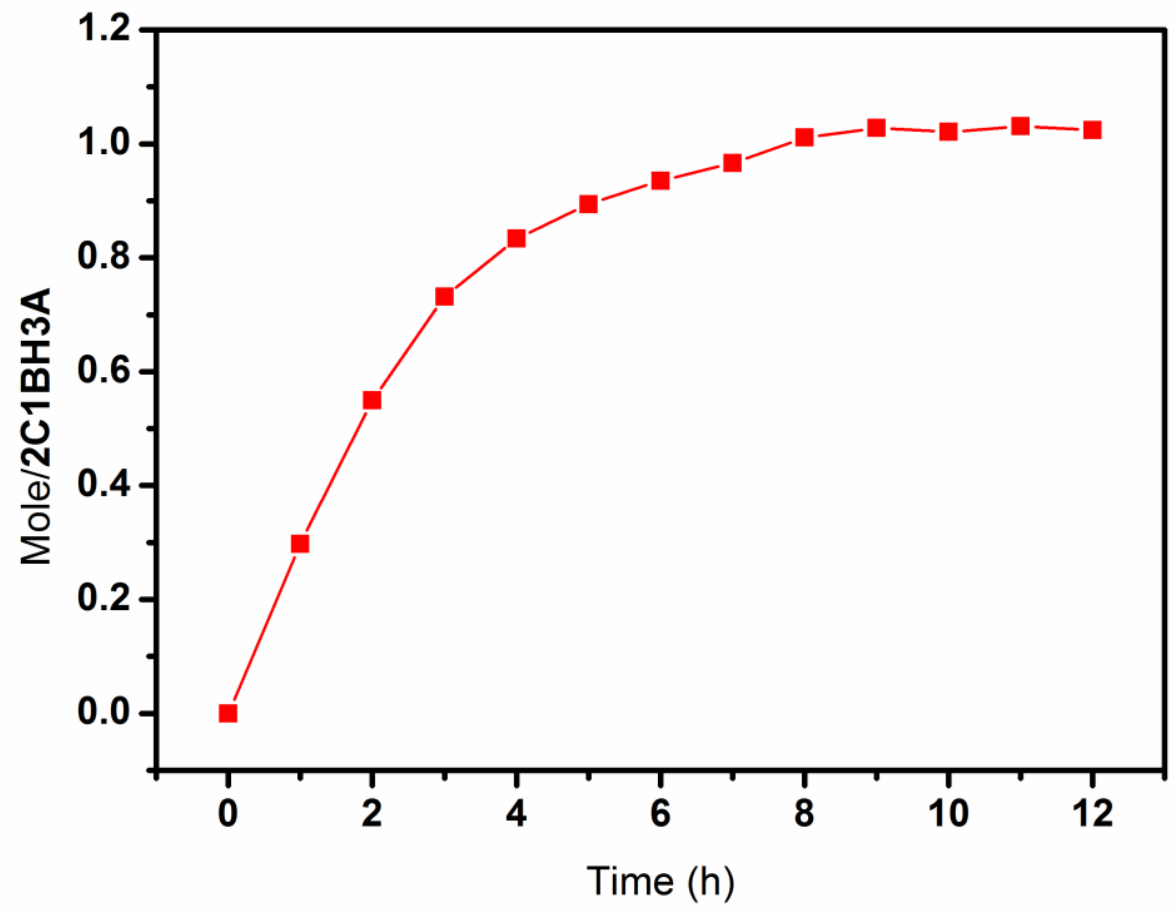

Figure S9. Time-dependent solid-vapor sorption plots of $\mathbf{1} \alpha$ for single-component $\mathbf{B z}$ vapor.

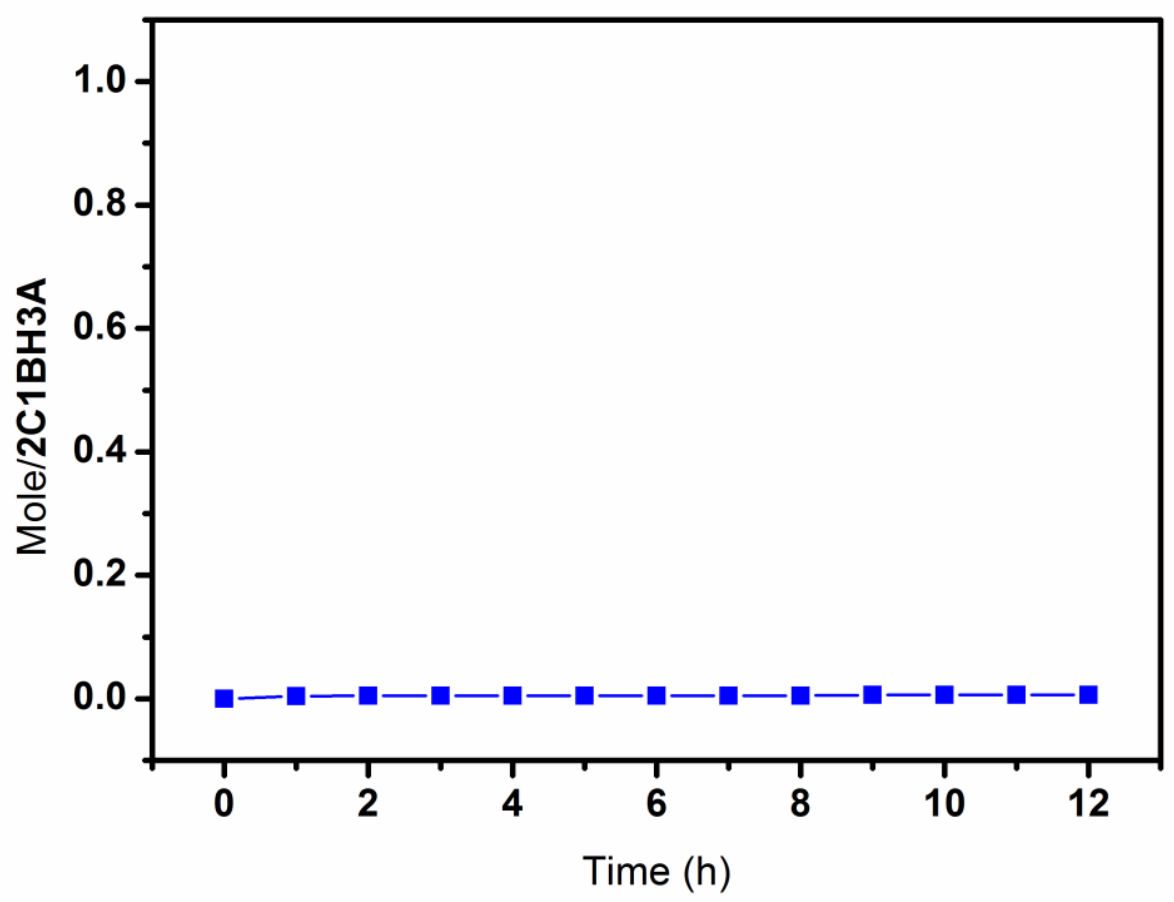

Figure S10. Time-dependent solid-vapor sorption plots of $\mathbf{1} \alpha$ for single-component $\mathbf{C y}$ vapor. 


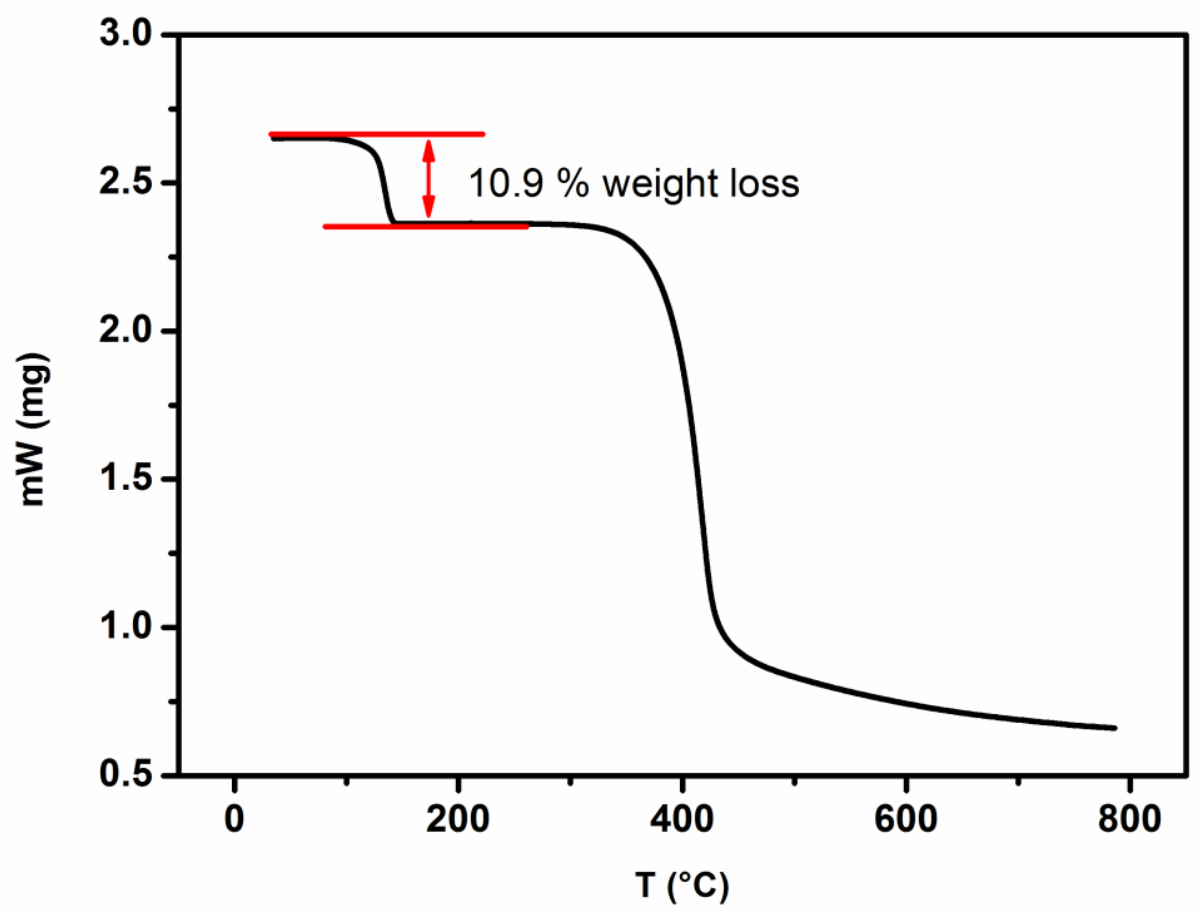

Figure S11. Thermogravimetric analysis of $\mathbf{1} \alpha$ after sorption of $\mathbf{B z}$ vapor for $12 \mathrm{~h}$. The weight loss below $150{ }^{\circ} \mathrm{C}$ can be calculated as one $\mathbf{B z}$ molecule per $\mathbf{1}$ molecule.

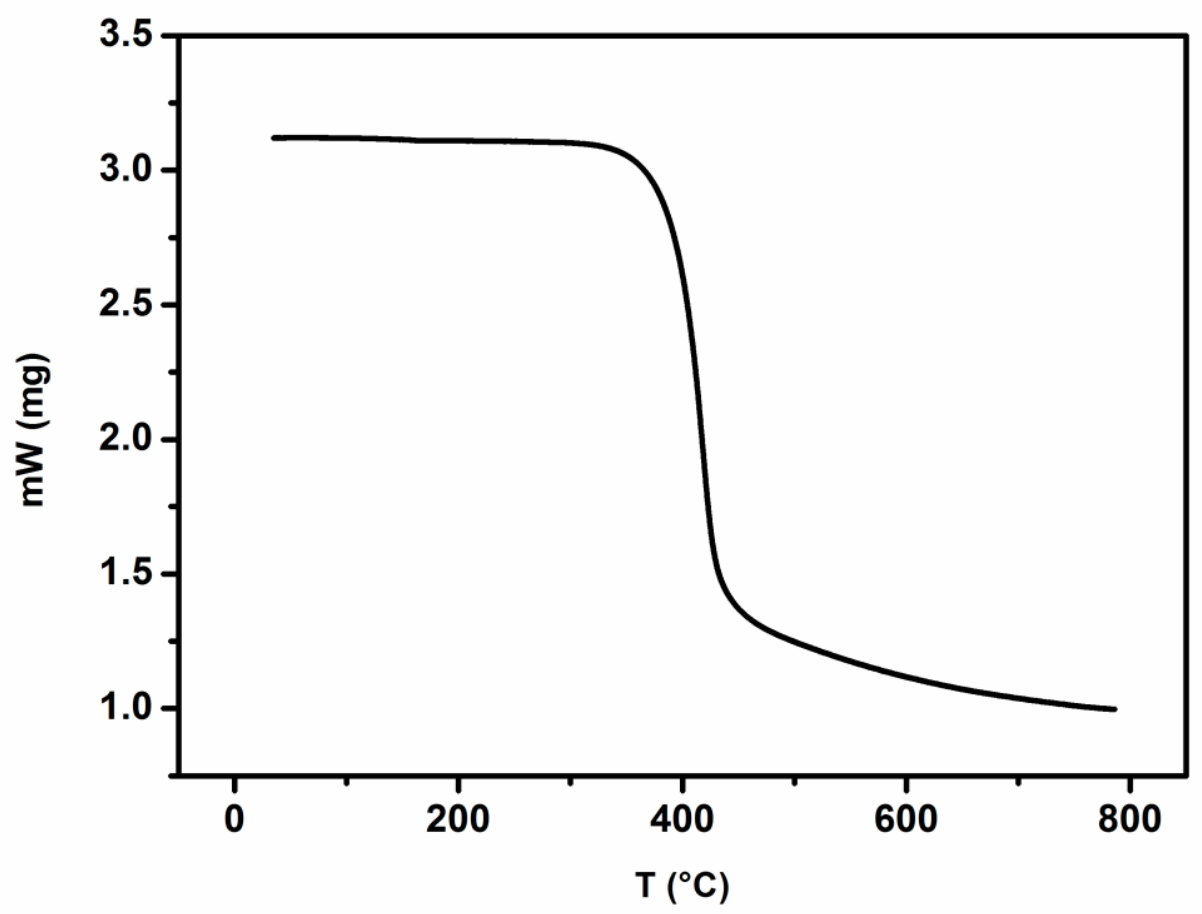

Figure S12. Thermogravimetric analysis of $\mathbf{1} \alpha$ after sorption of $\mathbf{C y}$ vapor for $12 \mathrm{~h}$. 


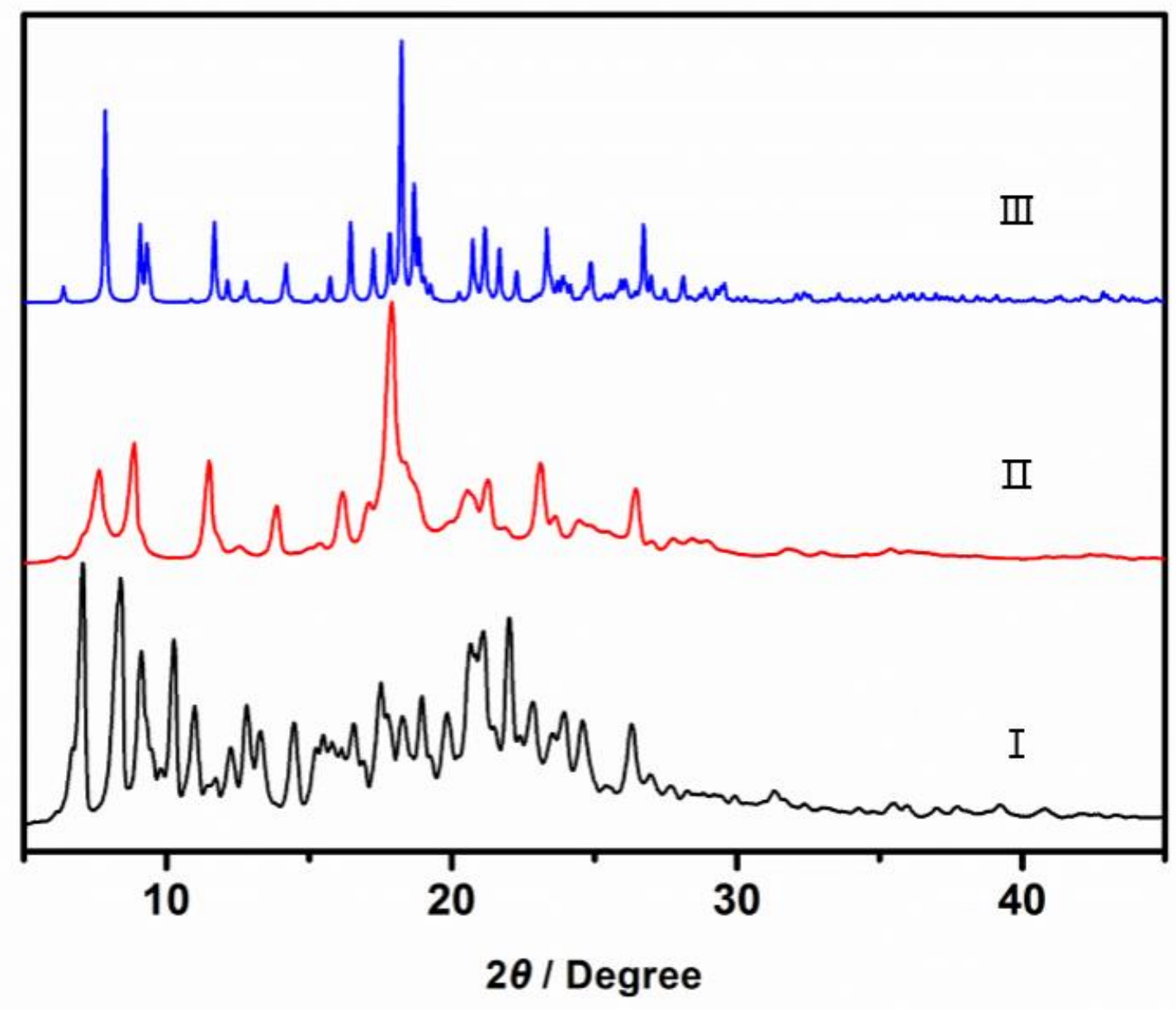

Figure S13. PXRD patterns of 1: (I) original 1 $\alpha$; (II) after adsorption of $\mathbf{B z}$ vapor; (III) simulated from single crystal structure of $\mathbf{B z} @ \mathbf{1}$. 


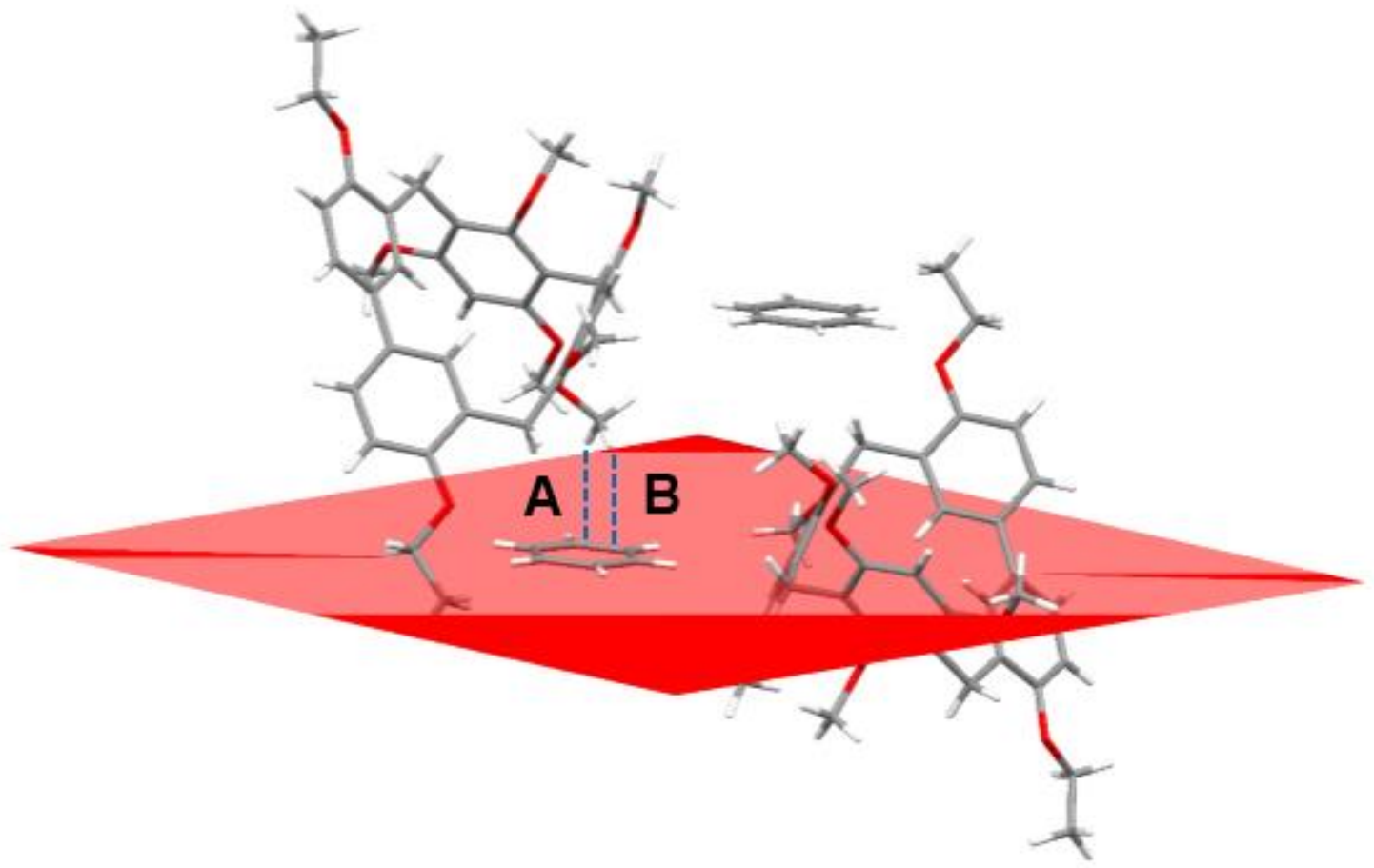

Figure S14. Illustration of $\mathrm{C}-\mathrm{H} \cdots \pi$ interactions between two $\mathrm{H}$ atoms on the methyl group of $\mathbf{1}$ and the benzene ring on Bz. $\mathrm{H}-\pi$-plane distances: $\mathbf{A}=2.712 \AA ; \mathbf{B}=2.932 \AA$.

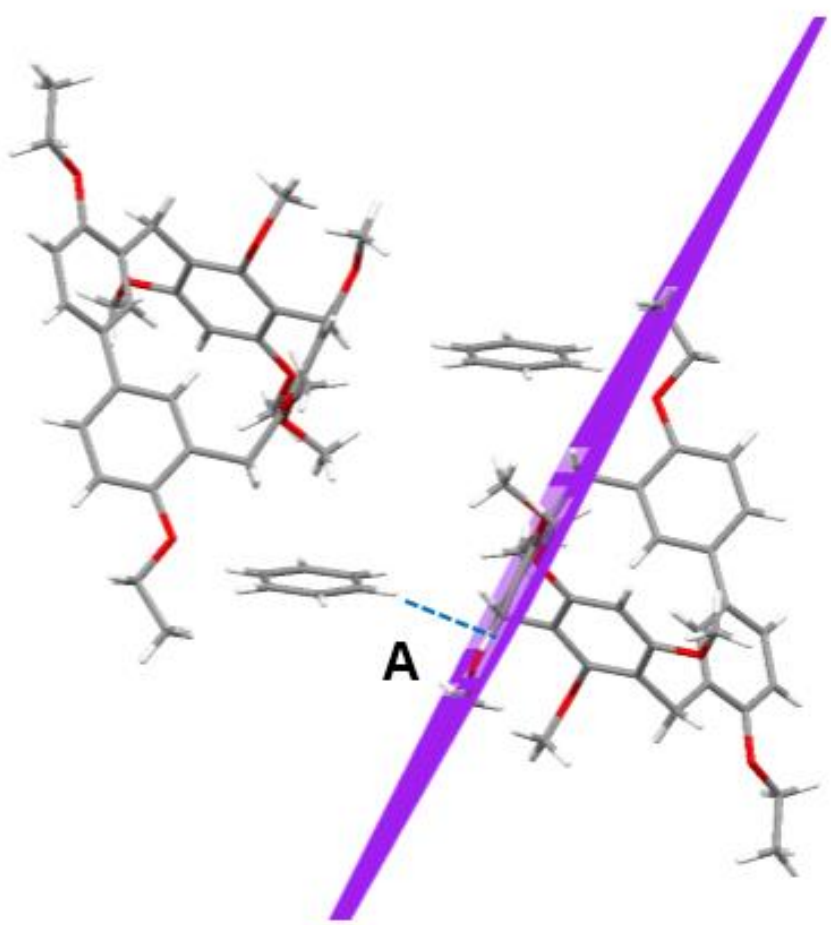

Figure S15. Illustration of a $\mathrm{C}-\mathrm{H} \cdots \pi$ interaction between an $\mathrm{H}$ atom on $\mathbf{B z}$ and a phenyl ring of $\mathbf{1}$. $\mathrm{H}-\pi$-plane distance: $\mathbf{A}=2.651 \AA$. 


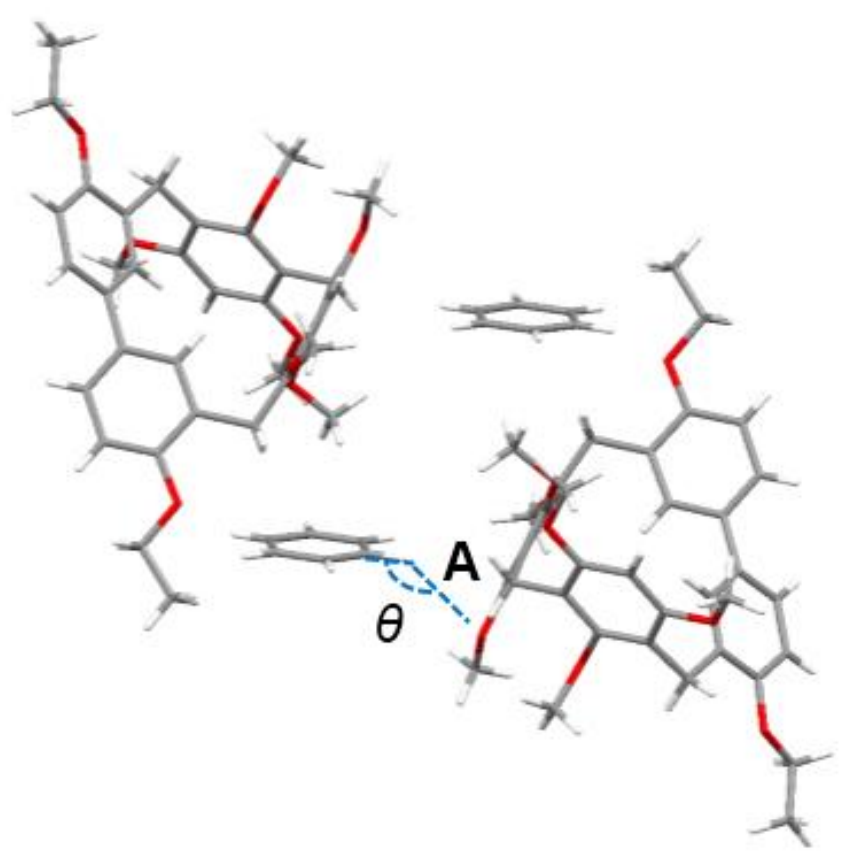

Figure S16. Illustration of a $\mathrm{C}-\mathrm{H} \cdots \mathrm{O}$ interaction between an $\mathrm{O}$ atom of $\mathbf{1}$ and an aromatic $\mathrm{H}$ atom of $\mathbf{B z}$. H-O distance: $\mathbf{A}=2.982 \AA$; $\mathrm{C}-\mathrm{H} \cdots \mathrm{O}$ angle: $\theta=125.34^{\circ}$.

\section{Uptake from a Bz/Cy Mixture by $1 \alpha$}

An open $5 \mathrm{~mL}$ vial containing $0.0200 \mathrm{~g}$ of guest-free $1 \alpha$ adsorbent was placed in a sealed $20 \mathrm{~mL}$ vial containing $1 \mathrm{~mL}$ of an equimolar $\mathbf{B z} / \mathbf{C y}$ mixture. Uptake by $\mathbf{1} \alpha$ was measured hour by hour by completely dissolving the crystals and measuring the ratio of $\mathbf{B z}$ or $\mathbf{C y}$ to $\mathbf{1}$ by ${ }^{1} \mathrm{H}$ NMR. The relative uptakes of $\mathbf{B z}$ and $\mathbf{C y}$ by $\mathbf{1} \alpha$ was also measured by heating the crystals to release the adsorbed vapor and detecting the relative amounts of $\mathbf{B z}$ and $\mathbf{C y}$ in the released vapor using gas chromatography. 


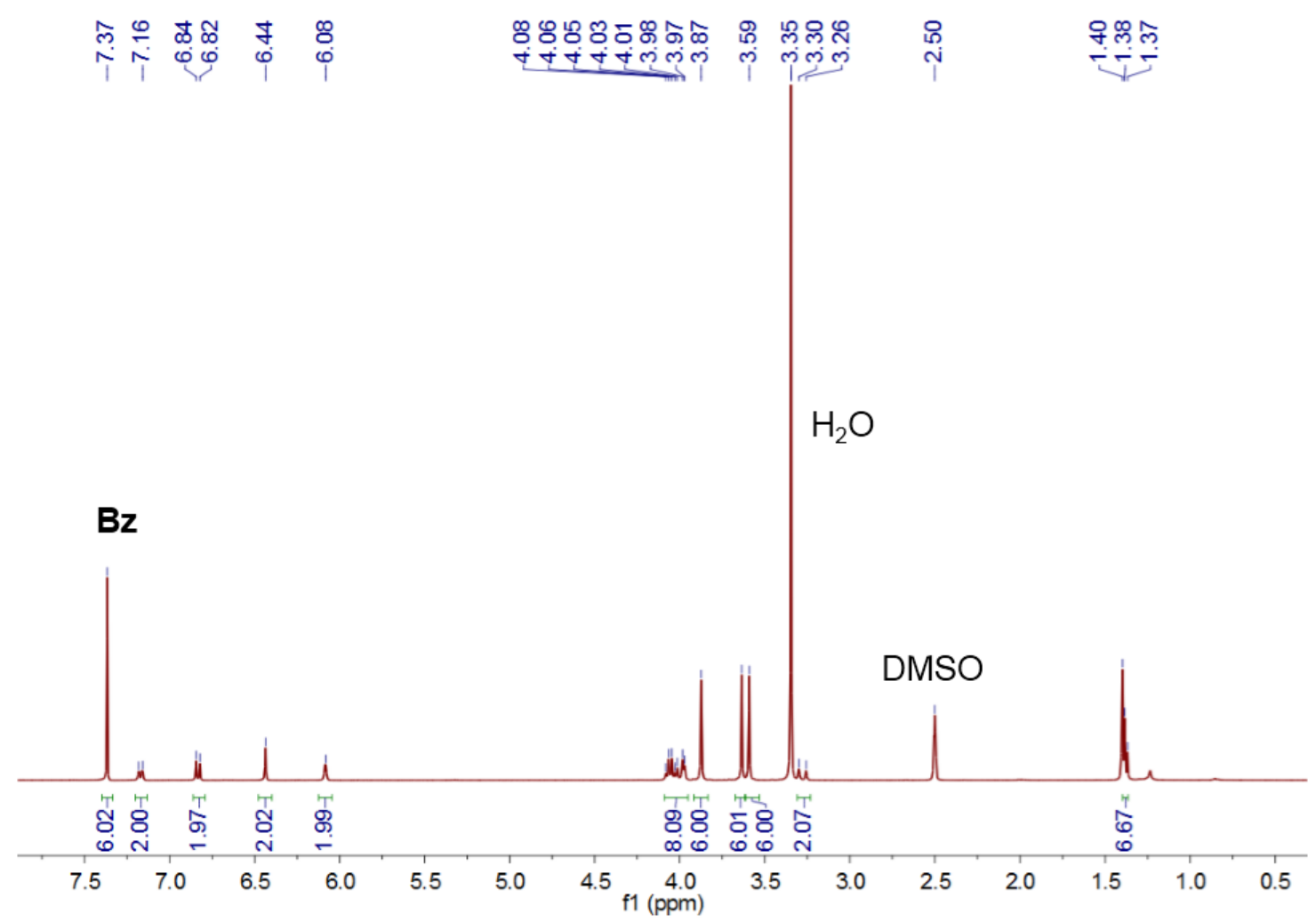

Figure S17. ${ }^{1} \mathrm{H}$ NMR spectrum (400 MHz, DMSO- $d_{6}, 293 \mathrm{~K}$ ) of $\mathbf{1} \alpha$ after sorption of an equimolar $\mathbf{B z} / \mathbf{C y}$ mixture vapor for $12 \mathrm{~h}$.

Bz, $97.54 \%$

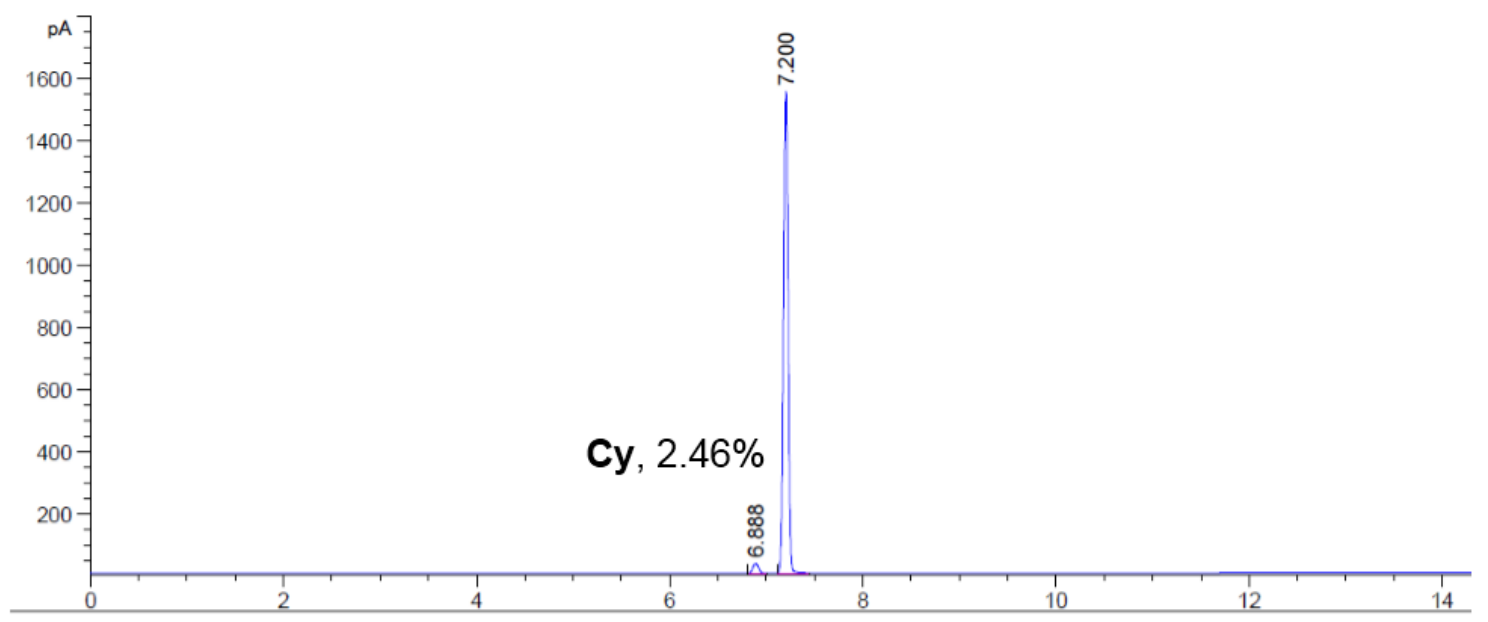

Figure S18. Relative uptakes of $\mathbf{B z}$ and $\mathbf{C y}$ adsorbed in $\mathbf{1} \alpha$ for $12 \mathrm{~h}$ using head space gas chromatography. 


\section{Recyclability of $1 \alpha$}

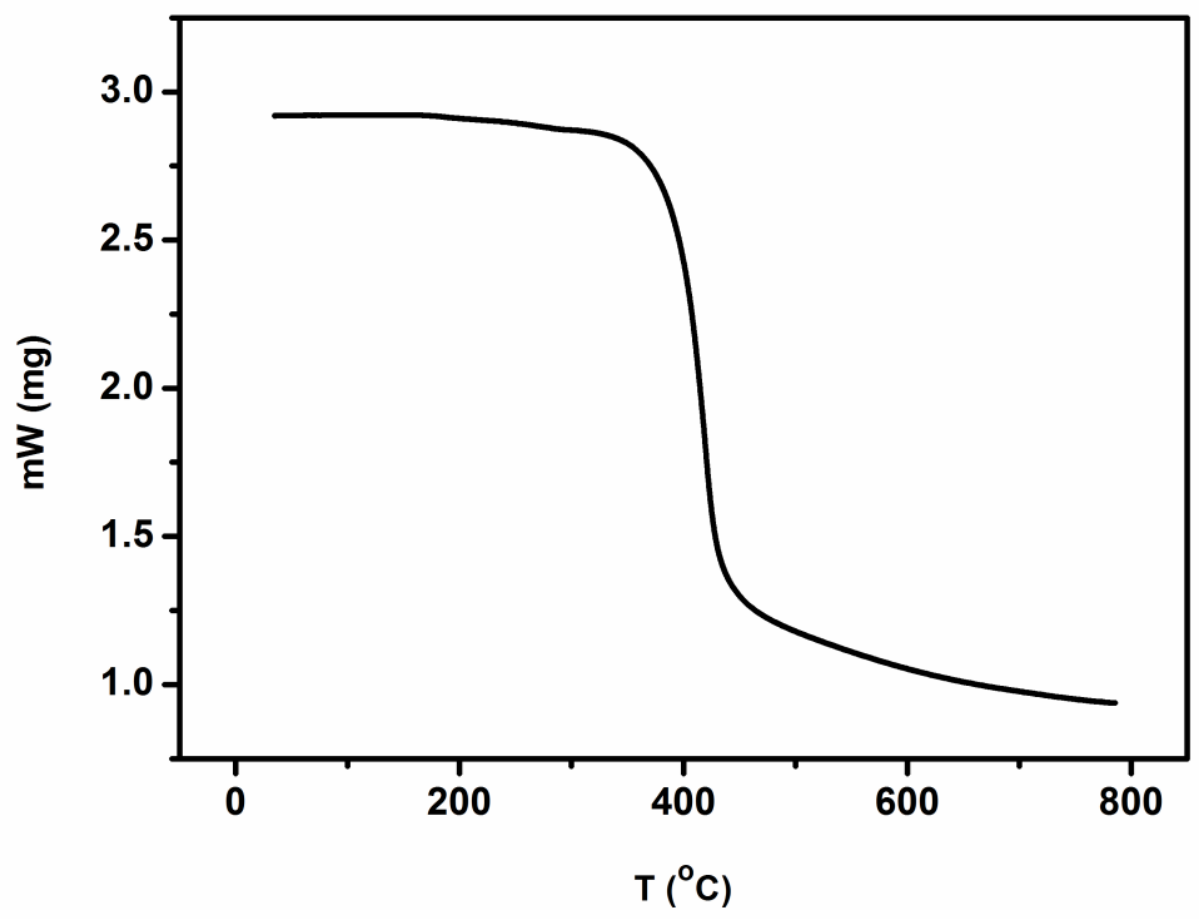

Figure S19. Thermogravimetric analysis of $\mathbf{B z} @ \mathbf{1} \alpha$ after heating at $100{ }^{\circ} \mathrm{C}$ under vacuum for $2 \mathrm{~h}$.

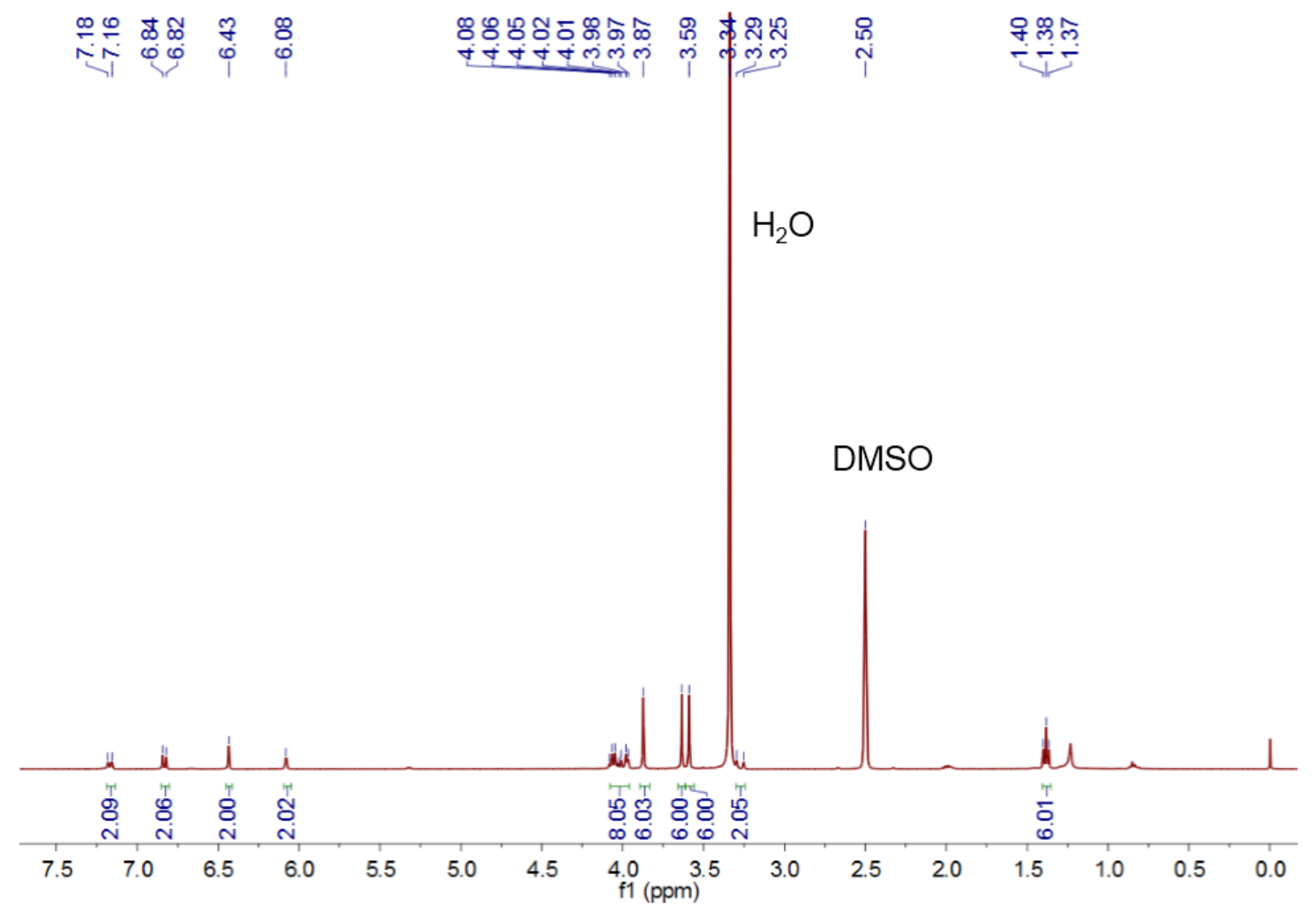

Figure S20. ${ }^{1} \mathrm{H}$ NMR spectrum $\left(400 \mathrm{MHz}, \mathrm{DMSO}-d_{6}, 293 \mathrm{~K}\right)$ of $\mathbf{B z} @ \mathbf{1} \alpha$ after heating at $100{ }^{\circ} \mathrm{C}$ under vacuum for $2 \mathrm{~h}$. 


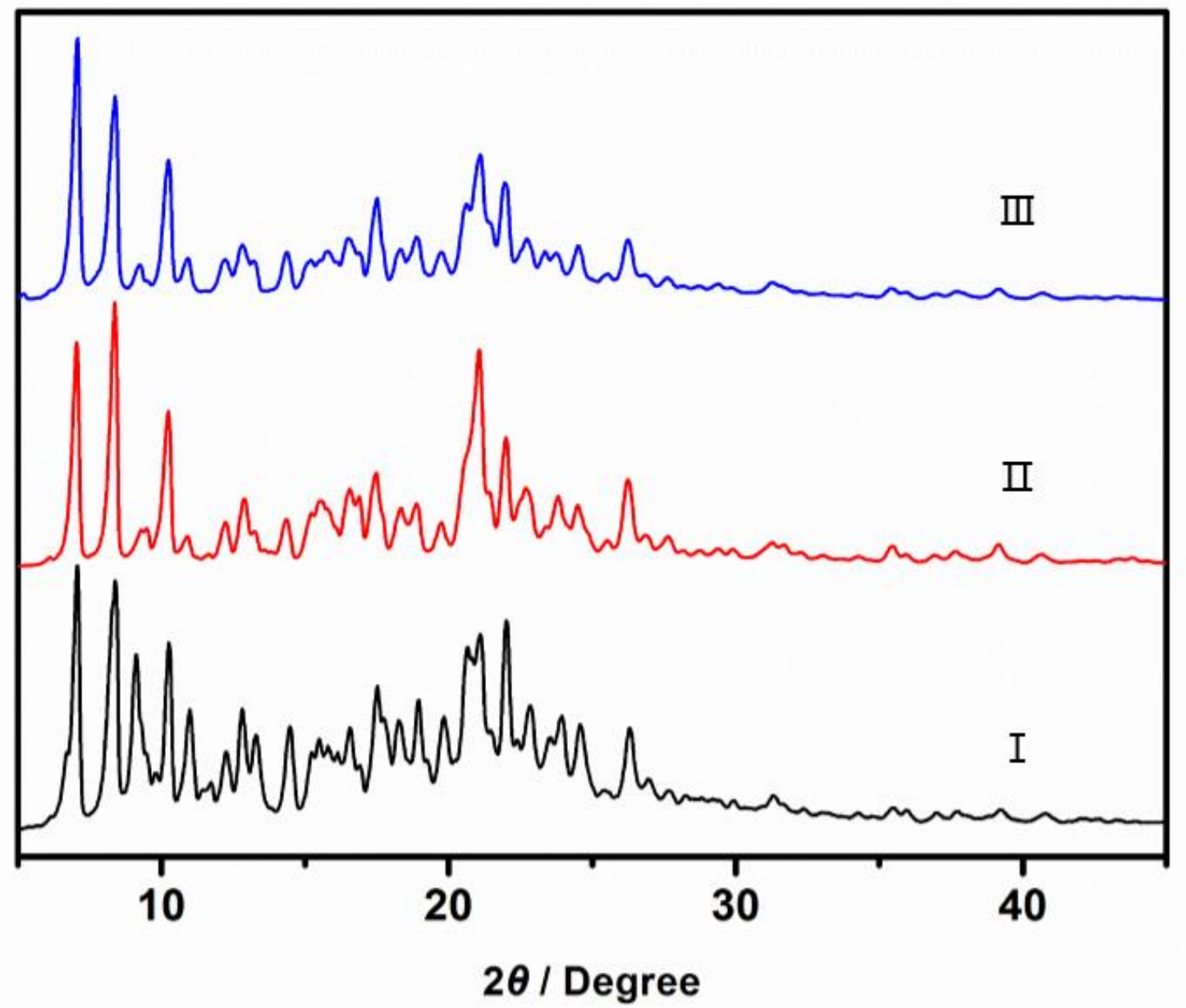

Figure S21. Powder X-ray diffraction patterns of 1: (I) original $1 \alpha$; (II) $\mathbf{1} \alpha$ after heating at $100{ }^{\circ} \mathrm{C}$ under vacuum for $2 \mathrm{~h}$; (III) $1 \alpha$ after 10 cycles.

\section{References}

S1. Zhou, J.; Yang, J.; Hua, B.; Shao, L.; Zhang, Z.; Yu, G. The Synthesis, Structure, and Molecular Recognition Properties of a [2]Calix[1]biphenyl-Type Hybrid[3]arene. Chem. Commun. 2016, 52, $1622-1624$. 